\title{
Older but Wilier: In-Group Accountability and the Development of Subjective Group Dynamics
}

\author{
Dominic Abrams, Adam Rutland, Lindsey Cameron, and Jennifer Ferrell \\ University of Kent
}

\begin{abstract}
To test social and cognitive variables that may affect the development of subjective group dynamics, the authors had 224 children between the ages of 5 and 12 years evaluate an in-group and an out-group and normative and deviant in-group members under conditions of high or low accountability to in-group peers. In-group bias and relative favorability to normative versus deviant in-group members (differential evaluation) increased when children were accountable to peers and as a function of perceptions of peer group acceptance of these members (differential inclusion). These effects were significantly larger among older children. Multiple classification ability was unrelated to judgments of group members. This study shows that the development of subjective group dynamics involves an increase in sensitivity to the normative aspects of the intergroup context.
\end{abstract}

Keywords: subjective group dynamics, accountability, in-group bias

Is social exclusion inevitable when a peer deviates from an in-group norm-for example, when a peer is disloyal by expressing enthusiasm about a different social group? Developmental psychologists have shown that peer rejection is prevalent in middle childhood and has considerable implications for children's psychological adjustment and life success (Dunn, 2004; Hymel, Vaillancourt, McDougall, \& Renshaw, 2002; Rubin, Bukowski, \& Parker, 1998). However, developmental research (e.g., Newcomb, Bukowski, \& Pattee, 1993) has typically explained peer rejection as resulting from the individual characteristics of the child being excluded (e.g., aggression, disruptive behavior). There has been relatively little research into the way social and cognitive variables combine in the development of children's relative judgments of normative and deviant peer group members within intergroup contexts when group memberships are salient (Ruble et al., 2004).

Given that children spend so much of their middle childhood among peers, either in educational or play settings, a key socialdevelopmental variable for intergroup social exclusion is likely to be the extent to which group members scrutinize children's behavior (i.e., peer group accountability). Therefore, it is important to understand how developmental changes in children's judgments of peers are sensitive to peer group accountability. The developmental subjective group dynamics (DSGD) model (Abrams \& Rutland, in press; Abrams, Rutland, \& Cameron, 2003), which

Dominic Abrams, Adam Rutland, Lindsey Cameron, and Jennifer Ferrell, Department of Psychology, University of Kent, Canterbury, United Kingdom.

Jennifer Ferrell is now at the Division of Psychology, University of Bedfordshire, Luton, United Kingdom.

This research was supported by a grant from the British Academy and by Economic and Social Research Council Grant R000230401. We extend our gratitude for feedback to John B. Nezlek and Arnaud Wisman. Much appreciation is extended to the teachers and children for their participation.

Correspondence concerning this article should be addressed to Dominic Abrams, Department of Psychology, University of Kent, Canterbury CT2 7NP, United Kingdom. E-mail: D.Abrams@kent.ac.uk integrates social psychological constructs with developmental phenomena, is useful here because it predicts that as children get older, their increasing social experiences and cognitive skills should facilitate more sophisticated judgments about other individuals. In addition, these judgments should become more responsive to relevant group differences and changes in the social context.

\section{Intergroup Context for the Research}

The present experimental study extended the DSGD model by investigating how accountability to other in-group members and multiple classification skills may affect the development of children's intergroup judgments and their evaluations of individual in-group members who differ in their adherence to prescriptive in-group norms. Following a study by Abrams, Rutland, Cameron, and Marques (2003), the present research was set in the intergroup context of summer activity schemes (referred to as summer school) in England. It is important to note that summer activity schemes are not comparable to North American summer camps, which children attend for a long time on a regular, often annual, basis and which may serve the development of a strong sense of cohesiveness. The schemes in the present research were nonresidential summer camps providing sports and other activities for children drawn from the local area. Typically, children attend for 1 or 2 weeks or a few days each week during the 6-week summer vacation period. Thus, the schemes are generally with children who are drawn from a number of different schools. The mix of children changes daily and according to the activities they pursue. These schools therefore provide a relatively minimal group membership, with no particular history of close intragroup relationships but with sufficient meaning and value that children evaluate their own summer school positively relative to others.

Abrams, Rutland, Cameron, and Marques (2003) found, among 6-7- and 10-11-year-olds, that the summer school context involved unambiguous loyalty norms about the expression of intergroup bias in favor of the in-group over the out-group summer 
school. While using the same intergroup context, the present research differed in several respects from Abrams, Rutland, Cameron, and Marques (2003). First, the present study involved children in a continuous age range between 5 and 12 years and 3 times as many participants, providing far greater statistical power for testing age-related changes. Second, children only evaluated members from the in-group. Third, and most important, there was no accountability manipulation in Abrams, Rutland, Cameron, and Marques (2003). In the present study, children were either accountable or not accountable to in-group members while they made judgments about the whole in-group and out-group and about a normative and deviant in-group member. As in previous research (Abrams, Rutland, \& Cameron, 2003; Abrams, Rutland, Cameron, \& Marques, 2003), the normative member expressed normative attitudes by favoring the member's in-group. The deviant member expressed positive attitudes toward both the in-group and the out-group, an attitude profile that children were found to regard as atypical in previous research (Abrams, Rutland, \& Cameron, 2003; Abrams, Rutland, Cameron, \& Marques, 2003). ${ }^{1}$

\section{Developmental Model of Subjective Group Dynamics}

Subjective group dynamics involve psychologically linking relevant intergroup attitudes to differences in judgments and evaluations of particular group members (see Marques \& Paez, 1994). The DSGD model holds that with greater cognitive and social sophistication, children should be more likely to integrate their preferences for different groups, with their evaluations of individuals being based on particular characteristics or behaviors. Specifically, the DSGD model proposes that children shift from evaluations of in-group and out-group members based on a simple preference for members of their in-group category (Aboud, 2003; Nesdale, 2001; Tajfel \& Turner, 1979) to judgments that differentiate among individuals within groups. This produces phenomena such as the black sheep effect, whereby a deviant out-group member may be regarded more favorably than a similar deviant in-group member (Marques, Yzerbyt, \& Leyens, 1988). In line with the developmental literature on social perspective taking (Quintana, 1998, 1999; Selman, 1971, 1980), older children should be more likely to recognize that deviance constitutes a departure from norms that other group members would want to preserve (i.e., deviance is a variation between individuals that is relevant to their group membership).

According to the DSGD model, older children sustain valued differences between in-group and out-group by differentially evaluating group members in favor of those who provide stronger support for in-group categories (see Abrams, Marques, Bown, \& Dougill, 2002; Abrams, Marques, Bown, \& Henson, 2000; Marques, Abrams, \& Serôdio, 2001). Children's capacity to focus on differences within groups therefore sustains, rather than diminishes, intergroup differences and bias because prejudice becomes targeted toward particular individuals.

A basic prediction of the developmental DSGD model is that intergroup and intragroup differentiation will be more closely linked among older than among younger children. An important variable in this process is children's understanding of differential inclusion. This is assessed by asking children how acceptable the normative and deviant in-group members are to other members of the in-group and out-group—-specifically, how other group mem- bers would feel toward the targets. ${ }^{2}$ Relative to the deviant member, the normative member should be perceived as more acceptable to fellow in-group members and less acceptable to out-group members. We regard differential inclusion to be an inference that children make on the basis of their social experience (i.e., learning about group dynamics, either in general or in particular) and their social perspective-taking ability. The DSGD model holds that the relationship between differential inclusion and differential evaluation should be more systematic among children with better social-cognitive ability and more social experience. All other things being equal, this relationship should be larger among older than among younger children (DSGD hypothesis). In addition, when children are more committed to supporting their in-group, they should show these effects more strongly (motivational hypothesis).

Consistent with these hypotheses Abrams, Rutland, Cameron, and Marques (2003) found that older children favored the normative in-group member over the deviant in-group member (differential evaluation) more strongly than did younger children. Moreover, differential evaluation was related to differential inclusion. In this experimental design, differential evaluation is a form of peer rejection or social exclusion, because the children are expressing a preference for one peer group member over another. In line with the motivational hypothesis, children who exhibited greater intergroup bias also showed greater intragroup bias in their differential evaluations of deviant and normative group members, although this effect was only marginally significant and requires further investigation within a summer school setting. This pattern of findings was echoed by Abrams, Rutland, and Cameron (2003) in the context of English children's support for the in-group (England) or out-group (Germany) soccer teams during the 2002 World Cup Soccer championships. The relationship between differential inclusion and differential evaluation was higher among older children, and it was further strengthened amongst children who were more committed to (identified with) their in-group.

The present research makes a new contribution to the model and to developmental research on social exclusion by examining whether the relationships between intergroup bias, differential evaluation, and differential inclusion are affected by the development of children's sensitivity to contextual normative factors and by their multiple classification skills.

\footnotetext{
${ }^{1}$ The term deviant is used to describe a person who adopts a counternormative position relative to prescriptive in-group norms. This does not necessarily imply deviance in terms of moral principles or any level of psychopathology. Prescriptive norms involve values, attitudes, and behaviors that group members want to uphold so as to sustain value and meaning for the group (see Marques, Abrams, Paez, \& Martinez-Taboada, 1998). In the DSGD framework, deviance from prescriptive norms can be operationalized in terms of loyalty to the in-group in an intergroup context. Expressions of favorable attitudes toward an out-group deviate from the loyalty norm that pervades many intergroup situations (see Zdaniuk \& Levine, 2001).

${ }^{2}$ Inclusion could be reflected in a variety of forms. Our index focuses only on the underlying feeling of attraction or repulsion that could motivate a range of behavioral responses.
} 


\section{Accountability}

Research has not yet investigated directly the prediction from the DSGD model that children's differential evaluations are related to the development of sensitivity to the prescriptive normative aspects of the intergroup context. One way to test this idea is to vary children's accountability to their peer group. Accountability affects intergroup judgments (Blanchard, Crandall, Brigham, \& Vaughan, 1994; Jetten, Spears, \& Manstead, 1997; Monteith, Deneen, \& Tooman, 1996). Both adults and children control their expressions of prejudice to reflect social desirability norms (e.g., Dovidio \& Gaertner, 1991; Plant \& Devine, 1998; Rutland, 2004; Rutland, Cameron, Milne, \& McGeorge, 2005; but see Doyle, Beaudet, \& Aboud, 1988, for a different conclusion in relation to racial attitudes). For example, children's level of specific concern about expressing prejudice affects their intergroup attitudes (Levy $\&$ Troise, 2001), and children have been found to moderate their attitudes depending on their audience (Banerjee, 2002; Banerjee \& Lintern, 2000; Jahoda, Thomson, \& Bhatt, 1972; Katz, Sohn, \& Zalk, 1975; Lawrence, 1991).

Children who are more self-conscious of their public selfpresentation moderate their intergroup biases (Abrams \& Brown, 1989). For example, among 10-12-year-olds, heightened public self-focus acted to increase national in-group bias (Rutland et al., 2005). Other evidence also shows that when norms are to express intergroup bias and the context involves salient intergroup rivalry, older children can show high levels of intergroup bias (BlackGutman \& Hickson, 1996; Rutland, 1999; Teichman, 2001).

Previous research (Marques et al., 1998, Experiment 2) demonstrated the potential effect of accountability on adults' intragroup judgments. Students were assigned to groups on the basis of a minimal (and baseless) categorization. They evaluated normative and deviant members of either the in-group or the out-group. Half of the participants were in an accountable condition; they were told that their answers would be shared with other in-group members. The remaining participants were not made accountable. Differential evaluation of group members, and specifically the black sheep effect (Marques et al., 1988), was significantly stronger in the accountable than in the control condition. The present research used a comparable manipulation to examine developmental aspects of responses to in-group accountability.

In general terms, we expected accountability to increase both intergroup bias and differential evaluation of normative versus deviant in-group members. However, we expected that older children's greater social experience and social perspective-taking skills should mean that they would be more responsive than younger children to peer norms in the accountable condition and, hence, should respond to accountability by showing more intergroup bias than younger children (intergroup accountability hypothesis).

There are several developmental reasons to advance this new hypothesis. Older children should have more and more varied experience of the dynamics of peer groups (Erwin, 1993; Hartup, 1983). This experience should give them a better understanding of the loyalty norms that prevail in many small groups (Zdaniuk \& Levine, 2001). As children gain in social experience, their greater understanding of small-group dynamics is reflected in greater expectations of differential inclusion and application of differential evaluations (Abrams, Rutland, \& Cameron, 2003; Ojala \& Nes- dale, 2004). Hence, it seems likely that older children will be more responsive to the implicit pressure to show in-group loyalty when they are accountable to in-group members (see Marques et al., 1998).

Developmental research on social perspective taking also suggests that children below 8 years of age are relatively poor at coordinating and integrating various psychological perspectives such as first-, second-, and third-person perspectives (Quintana, 1994, 1999; Selman, 1971, 1980). Therefore, younger children may be less likely to feel pressure from peer group accountability and less capable of coordinating their intergroup and intragroup judgments in response to anticipated peer reactions.

In line with Marques et al. (1998), we expected older children to be more responsive to the accountability manipulation by showing greater intergroup bias and greater differential evaluation. We did not expect accountability to affect differential inclusion judgments, because these are a measure of beliefs about other group members rather than evaluations of those members. We did, however, expect accountability to affect the way children link their differential inclusion judgments to their evaluations of members. Therefore, a further new hypothesis tested in the present study was that because older children should be more able to understand the normative expectations of the peer group, the impact of accountability on the evaluations of group members will be largest among those older children who also perceive higher differential inclusion (intragroup accountability hypothesis).

\section{Multiple Classification Skill}

The social-cognitive skill to differentiate among individuals using a multitude of psychological categories and traits seems to emerge from around the age of about 8 years, as illustrated in the developmental literature on person perception (e.g., Alvarez, Ruble, \& Bolger, 2001; Barenboim, 1978, 1981; Livesley \& Bromley, 1973; Peevers \& Secord, 1973; Ruble \& Dweck, 1995). Cognitive-developmental theory (CDT; Aboud, 1988; Katz, 1976; Lambert \& Klineberg, 1967) holds that children's judgments of in-group and out-group members change from being group-based to being outcomes of more complex, person-based processes as children develop multiple classification skills. That is, children judge people on multiple dimensions, of which a particular group membership is only one. Consequently, it has been argued, intergroup biases in many domains reduce as children get older, particularly after the age of 7 or 8 .

Previous tests of the DSGD model (Abrams, Rutland, \& Cameron, 2003; Abrams, Rutland, Cameron, \& Marques, 2003) revealed that older children do focus more on individual differences, consistent with the idea that older children make greater use of multiple classification (Aboud, 1988; Bigler, 1995; Katz et al., 1975). However, in contrast to the predictions of CDT, greater differentiation between individual group members was associated with higher rather than lower intergroup bias.

In these previous DSGD studies, there was no independent assessment of multiple classification ability and, thus, no opportunity to test whether multiple classification ability is related to the intergroup or intragroup judgments. Therefore, the present research examined whether children's ability to use multiple bases of classification is related to their evaluations of groups and group members. On the basis of CDT, we expected better multiple 
classification skill to be associated with reduced intergroup bias and increased differential evaluation of particular group members.

We are agnostic about whether the development of multiple classification skill may be relevant for the onset of differential inclusion judgments. It may be that multiple classification ability would help children to understand that other members of groups can use multiple levels of judgment, but it seems more likely that such understanding may require the development of social perspective-taking ability.

If the development of intergroup bias, differential inclusion, or differential evaluation is a result of developing multiple classification abilities, the relationship between age and these other variables should be mediated statistically, at least in part, by multiple classification skill. We label this original hypothesis the multiple classification hypothesis.

\section{Relationship Between Intergroup and Intragroup Judgments}

The DSGD model predicts that across middle childhood, intergroup bias should become more strongly positively related to intragroup biases. Consistent with this idea, Abrams, Rutland, Cameron, and Marques (2003) found that the relationship between intergroup bias and differential evaluations strengthened with age. Abrams, Rutland, and Cameron (2003) also found that children who identified more strongly with the in-group also showed a stronger relationship between differential inclusion and differential evaluations. This finding is consistent with the idea that children who care more about in-group superiority will apply their understanding of differential inclusion more to their own evaluations of group members. We did not expect accountability to change either of these effects, because we expected accountability to elevate both intergroup bias and differential evaluation rather than to change the relationship between them. However, because the present study used a slightly different index of intergroup bias, the replication of these previous effects provides a useful convergentvalidity test of the model as a whole.

\section{Summary of Hypotheses}

We expected the intergroup context to be sufficiently engaging that children would show in-group bias (favoring the in-group as a whole over the out-group as a whole) and that children would favor the normative member over the deviant member. The DSGD model concerns the relationship between intergroup and intragroup differentiation. These variables are based on three measures: general intergroup bias (in-group minus out-group ratings), differential evaluation (normative minus deviant member ratings), and differential inclusion (differences in the perceived attractiveness of the normative and the deviant member to the in-group vs. the out-group). Children who express more intergroup bias should relate their expectations about differential inclusion more systematically to their differential evaluation of group members. Specifically, we predicted that the development of cognitive ability and social experience amongst older children should result in stronger associations between the different forms of differentiation in older children than in younger children (DSGD hypothesis). It was also anticipated that the association between differential inclusion and differential evaluation would be larger among children showing more intergroup bias (motivational hypothesis).

Originally, we assumed that these DSGD effects are related to the development of children's sensitivity to peer group norms. Therefore, there should be different developmental trends in judgments at both the intergroup and intragroup levels in the accountable and nonaccountable conditions (intergroup and intragroup accountability hypotheses).

On the basis of CDT, we also provide a novel examination of the multiple classification hypothesis that older children should have better multiple classification skill, which should be associated with less intergroup bias and more intragroup differentiation. Thus, we expected that multiple classification ability might mediate the relationship between age and the intergroup and intragroup differentiation measures.

\section{Method}

\section{Design and Participants}

Our predictions did not assume that specific ages should be associated with specific differences in the operation of subjective group dynamics - namely, that there should be age-related changes during middle childhood. We therefore examined children between 5 and 12 years of age, and we assumed that age as a variable serves as a proxy for the continuous development of both socialcognitive factors and social experience. Age was distributed evenly over years, with an average of 25.5 children within each year band between 5 and 12 years (range $=4.75-12.83$ years; $M=$ $9.00, S D=2.25$ ). To maximize statistical power, we treated age as a continuous independent variable rather than grouping it into categories (see MacCallum, Zhang, Preacher, \& Rucker, 2002). The second independent variable was condition (accountable vs. control), to which participants were assigned randomly.

The participants were 228 children from six different summer schools within a locality 50 miles from London, United Kingdom. On the basis of 2003 U.K. Census data, $96.6 \%$ of the population in this locality is classified as White British. The locality is ranked 190th of 354 districts in the English Indices of Multiple Deprivation. As compared with the national average (51.0\%), 68.3\% of households were classified as of medium to high socioeconomic status (ranging from small employers to managers and professions). Thus, the children could be described as predominantly from middle-class backgrounds. Assignment to condition was random within each school, $\chi^{2}(5, N=228)=6.09, p=.30$. Forty percent of the participants were female, and gender was evenly distributed between conditions, $\chi^{2}(1, N=228)=0.40, p=.53$. Gender was evenly distributed across age (point biserial $r=-.10$, $p>$.13). Data were incomplete for 5 children, and these were among the 21 excluded from the overall analyses.

\section{Procedure}

All children participated individually under the supervision of a female experimenter. The experimenter interviewed the younger children with the questionnaire in front of them. The older children, given their more advanced reading ability, were allowed to self-complete the questionnaire in the presence of the experimenter, who sat directly next to each child. The experimenter 
monitored all children's progress through each question, ensuring and checking with them whether they understood the questions. This procedure was used to ensure that the baseline accountability cues were similar for children in all age groups (see also Abrams, Rutland, \& Cameron, 2003) and that only the accountability to in-group varied.

\section{Materials}

Children were given a questionnaire and either completed it themselves or had each question read out by a female researcher, with the child asked to point to the answer. The front page explained, "We are asking children about the Summer School. Most of the questions can be answered by putting a tick next to a picture of a face." There followed a series of questions about the weather that day, with an explanation of which face to tick to describe it. Each point on the 5-point scale was represented by a circular "feeling face." The mouth on each face varied, moving from a downward position (1) through horizontal (3) to a large smile (5). This page was used to check that participants understood how to use the response scale.

Accountability manipulation. At this point, the accountability manipulation was introduced. In the accountable condition, children were told that they would be asked some questions about the summer schools and that afterward their answers would be shown to other children from their summer school too. In the control condition, children were told that no one else would see the answers they gave to the questions.

Intergroup bias. The next page tapped the child's general judgment of his or her Summer School by asking. "How much do you like your Summer School Scheme at [school]?" A parallel question was asked about the other school: "How much do you think you would like to be at the Summer School at [other school] instead?" For these two questions tapping in-group and out-group evaluation, the face scales were anchored with 1 (not at all) and 5 (very much). We computed a composite measure of general intergroup bias by subtracting support for the out-group from support for the in-group.

Member information. The next page presented "some of the things said by children who went to [in-group summer school] last year." Previous research has revealed in-group gender bias amongst children (e.g., Bigler, 1995; Martin, 1989; Powlishta, 1995; Yee \& Brown, 1994). To avoid confounding with gender bias, we referred to the children by initial letters and did not mention their gender. To ensure that the normative position was clearly established, we included two normative children and one deviant child. The children were presented with statements ostensibly made by 3 children, labeled $N D, J R$, and $D M$. JR was always the deviant member, and ND and DM were normative members.

The first normative member, ND, said, "I really like the [ingroup] summer school, there's lots of different things you can do, the [in-group summer school] is a great place to be during the summer." The deviant member, JR, made a positive statement about both the in-group and the out-group school: "All the things you can do at [in-group] Summer School are great fun, but I think the [out-group] Summer School would be good because there are lots of exciting things to do there." The second normative member, DM, agreed with ND and said, "The [in-group] summer school is good for sports and games and the people are really nice at the [in-group] summer school." Abrams, Rutland, Cameron, and Marques (2003) demonstrated that these statements reflected the normative and deviant positions in this context. The out-group school was held constant regardless of children's own school. The out-group school scheme was long-standing and large, and the name of the school was well-known to all of the children. All of the participating summer schools were within a 15-mile radius of the out-group summer school.

The rest of the questionnaire asked about one of the normative members and the deviant member. Half of the children answered questions about ND and JR, and half answered questions about $\mathrm{DM}$ and JR. The order of presentation of questions about the normative member and the deviant member was also counterbalanced. Children were first reminded of what the particular member had said, and then they answered several questions. The first two questions constituted a perceptual accuracy check to see whether participants understood which preferences the member had expressed: "What does [member] feel about being at the [summer school]?" "What do you think [member] would feel about going to the [other summer school] instead?"

Differential inclusion. After these manipulation-checking items, two questions using the face scales to measure perceived same-group inclusion and other-group inclusion were asked. These were included to see whether children understood the social implications of the members' attitudes in terms of their likely acceptability to members of each group. The questions were as follows: "How do you think other children at [summer school] would feel towards [member]?" "How do you think children who go to the [other summer school] would feel toward [member]?"

To calculate an index of differential inclusion, we subtracted the out-group inclusion rating from the in-group inclusion rating. In previous research, Abrams, Rutland, and Cameron (2003) and Abrams, Rutland, Cameron, and Marques (2003) found that this score was typically positive for a normative member and negative for a deviant member. Then the score for the deviant member was subtracted from the score for the normative member. The higher the score, the more the participant expected the normative member to be accepted by the in-group and rejected by the out-group and the more they expected the deviant member to be accepted by the out-group but rejected by the in-group.

Differential evaluation. Member evaluations were examined by asking two questions: "How do you feel towards [member]?" "How much would you like to be [member's] friend?" Responses were made using the feeling face scales. The average of the ratings of the deviant member was subtracted from the average of the ratings of the normative member to obtain an index of differential evaluation. A more positive score represented stronger preference for the normative over the deviant member.

Multiple classification task. Finally, we presented children with three red $X \mathrm{~s}$, three green $X \mathrm{~s}$, three red triangles, and three green triangles on a separate page. Below these objects was a box bisected horizontally and vertically to comprise a $2 \times 2$ grid. Children were instructed as follows: "Think about which of these objects belong together. Put the objects in the grid below. Put objects that belong together in the same square of the grids. You do not have to use all the grid squares." Younger children performed this task with cutouts of the shapes, whereas older children drew the shapes using red and green pens. The experimenter then asked for a justification of their sorting behavior, if it correctly 
involved two dimensions, by asking, first, "Why are these items together in this group?" and, second, "Why are these shapes put in a separate box from these shapes?" However, if the child sorted the objects incorrectly (i.e., by sorting on only one dimension or with no pattern of classification), the experimenter showed the child a correct sorting of the objects. Next, the experimenter asked the child to justify why this was the correct way to sort the objects, using the same justification questions given above.

This task is modeled closely on the nonsocial classification task used by Bigler and Liben (1992); it was scored according to Golbeck's (1983) method (based on Inhelder \& Piaget, 1964). A child who incorrectly sorted the objects and was unable to justify the classification when shown the correct sorting method, was assigned a score of 0 . In contrast, a child who sorted the objects on both dimensions but was unable to correctly justify why, was assigned a score of 1 . A score of 2 was assigned if the objects were sorted incorrectly, but the child was able to justify the sorting method when shown the correct classifications. Finally, if the objects were correctly sorted with a correct justification, the child was assigned a score of 3 . To check whether the presumption of ordinality of this scaling was appropriate, we also classified these data in three different dichotomous forms (correct vs. incorrect multiple classification, correct vs. incorrect justification, incorrect vs. either correct or correctly justified classification).

\section{Results}

First, we analyzed the data to investigate possible effects of school and gender. Previous research has revealed pronounced in-group gender bias amongst children (e.g., Bigler, 1995; Martin, 1989; Powlishta, 1995; Yee \& Brown, 1994). Gender was not strictly relevant to the present hypotheses or to the comparison between the summer schools, and there were no a priori reasons to expect gender to affect responses. As expected, there were no significant multivariate main effects or interactions involving either gender or school. As a further precaution, we used hierarchical linear modeling to check whether school (as a Level 2 random variable) accounted for a reliable proportion of the variance in the dependent measures and to be sure that the statistical effects at Level 1 (individuals) were not the result of deflated standard errors owing to Level 2 variation. We followed the procedures recommended by Nezlek (2001). Initially, all Level 1 coefficients were modeled as random. Coefficients were fixed following recommendations offered by Nezlek. (Details of error terms that were fixed and the bases for fixing them are available on request from D.A.) The analysis revealed no reliable Level 2 variation, and the Level 1 results were not changed by inclusion of Level 2 data. Moreover, all of the intraclass correlations were small $(<.07)$ and nonsignificant, indicating that there was unlikely to be a substantial risk of deflated Level 1 standard errors. Therefore, the analyses reported below collapse across school as well as gender (see also Footnote 6 [presented later]).

\section{Manipulation Check: Perceptual Accuracy}

Data from 8 children were excluded because it was evident during testing that they were not paying attention to the task. Two of these were among the 5 already excluded owing to noncompletion. On examination of the perceptual accuracy measure data from all children, these 8 were among the 18 (7.6\%) excluded participants who had inaccurately judged the deviant member to be more favorable to the in-group than the normative member. Younger children were more likely to have failed the manipulation check $(r=-.23, p<.001)$. Data for the remaining 207 children were used for subsequent analyses. The initial and final numbers included for analysis reflected the availability of children at the time of the study. Within each year group, the initial and final numbers, respectively, were 25 and 20 (age 5), 28 and 23 (age 6), 31 and 27 (age 7), 31 and 30 (age 8), 31 and 30 (age 9), 25 and 24 (age 10), 22 and 21 (age 11), and 32 and 32 (age 12). Random assignment to condition was successful within all age levels (maximum difference between cell sizes in the accountable and the control condition $=5$, modal difference $=1), \chi^{2}(7, N=207)=4.54, p=$ .72 .

\section{Order Effects}

Abrams, Rutland, Cameron, and Marques (2003) used a fixed order of presentation of group members. In the present research, order was counterbalanced. We examined all of the main dependent variables described below to see whether there were any effects of order of presentation of the normative and deviant members. Across all the measures, no differences were significant (smallest $F[206]=0.00$; largest $F[206]=0.56, p=.45$ ). Therefore, order was not included as a factor in subsequent analyses.

\section{Hypothesis Tests}

The means for measures of general group evaluations and member inclusion and evaluation as a function of condition are shown in Table 1. Correlations among these variables are presented in Table 2. Our theoretical interest is in differences between judgments of the in-group and the out-group and differences between judgments of normative and deviant members. Therefore, the analyses focus on the magnitude of these differences (cf. Judd, Kenny, \& McClelland, 2001). The DSGD hypotheses were tested using multiple regression analyses. For these analyses, we followed the procedures recommended by Aiken and West (1991), including centering of independent variables (condition and age) before calculation of interaction effects.

Intergroup accountability hypothesis. As expected, intergroup bias differed significantly from zero, $t(205)=17.60, p<.001$, $\eta^{2}=.60$. There were no significant main effects for age or condition, $t \mathrm{~s}(203)<0.70$, multiple $R \mathrm{~s}=.053$, but there was a significant Age $\times$ Condition interaction, $\beta=.16, t(202)=2.27$, $p<.05$, multiple $R=.17$. As predicted by the intergroup accountability hypothesis, simple slopes analysis showed that among younger children, there was no significant effect of condition, $B=$ $-0.09, t(202)=1.59, p>.12$, whereas older children showed significantly more bias in the accountable than in the control condition, $B=0.13, t(202)=2.43, p<.05$. Also consistent with this hypothesis, in the control condition, the relationship between age and bias was nonsignificant $(r=-.11)$, but in the accountable condition, children expressed stronger intergroup bias with age $(r=.19, p=.05)$.

Differential inclusion. As expected, differential inclusion was significantly different from zero $(M=1.46, S D=2.44), t(204)=$ $8.54, p<.001, \eta^{2}=.26$. We regressed age, condition, and their 
Table 1

Means and Standard Deviations for Measures of Group Inclusion and Evaluation as a Function of Condition (Control or Accountable) and Type of Member (Normative or Deviant)

\begin{tabular}{|c|c|c|c|c|c|c|c|c|}
\hline \multirow[b]{3}{*}{ Variable } & \multicolumn{4}{|c|}{ Control } & \multicolumn{4}{|c|}{ Accountable } \\
\hline & \multicolumn{2}{|c|}{ Normative } & \multicolumn{2}{|c|}{ Deviant } & \multicolumn{2}{|c|}{ Normative } & \multicolumn{2}{|c|}{ Deviant } \\
\hline & $M$ & $S D$ & $M$ & $S D$ & $M$ & $S D$ & $M$ & $S D$ \\
\hline Inclusion by in-group & 4.00 & 0.87 & 3.67 & 1.12 & 4.29 & 0.87 & 3.56 & 1.24 \\
\hline Inclusion by out-group & 3.12 & 1.26 & 3.95 & 1.02 & 3.02 & 1.37 & 3.98 & 1.07 \\
\hline Evaluation & 3.88 & 1.09 & 3.57 & 1.14 & 4.12 & 1.10 & 3.25 & 1.24 \\
\hline
\end{tabular}

Note. Scores on each variable could range from 1 (negative) to 5 (positive). The inclusion measures tapped how a child believed members of the in-group or the out-group would feel toward the target member. Evaluation tapped the child's own feelings toward the member. Pairwise comparisons within rows revealed that means for the normative versus deviant members differ significantly both within and between conditions $(p<.05)$. For each type of member, pairwise comparisons of inclusion by in-group versus inclusion by out-group showed significant differences $(p<.05)$ except for the deviant member in the control condition $(p=.054)$.

interaction term onto differential inclusion. This revealed a significant effect of age, $\beta=.29, t(203)=4.30, p<.001$, and a marginal effect of condition, $\beta=.12, t(203)=1.80, p<.08$, multiple $R=.31$, but no Age $\times$ Condition interaction, $\beta=.02$, $t(203)=0.23$. Differential inclusion increased as a function of age, consistent with previous findings (Abrams, Rutland, \& Cameron, 2003; Abrams, Rutland, Cameron, \& Marques, 2003) and the assumption that older children should have a clearer understanding of group dynamics in an intergroup context.

Differential evaluation. The DSGD model anticipates that normative in-group members should be favored over deviant members. As shown in Table 1 , this was the case. ${ }^{3}$ As expected, differential evaluation was significantly related to differential inclusion $(r=.28, p<.001){ }^{4}$ We tested the DSGD and intragroup accountability hypotheses by regressing centered scores for differential inclusion, age, condition, and their two-way and three-way interaction terms onto differential evaluations.

DSGD hypothesis. The DSGD hypothesis is that the relationship between differential evaluation and differential inclusion should strengthen as children get older. This implies a significant Age $\times$ Differential Inclusion interaction effect on differential evaluation. Consistent with this hypothesis, there was a significant Age $\times$ Differential Inclusion interaction, $\beta=.34, t(202)=3.61$, $p<.001$.

Intragroup accountability hypothesis. This hypothesis is based on the premise that older children should be more able to understand the normative expectations of the peer group. Thus, the impact of accountability on the evaluations of group members will be strongest among older children who also perceive higher differential inclusion. This implies a significant Age $\times$ Differential Inclusion $\times$ Condition interaction.

The effect of condition was significant, $\beta=.20, t(199)=2.84$, $p<.005$. As expected, children showed stronger differential evaluation in the accountable condition. Consistent with the intragroup accountability hypothesis, the Age $\times$ Differential Inclusion interaction for the DSGD hypothesis was qualified by a significant three way interaction between Age $\times$ Condition $\times$ Differential Inclusion interaction, $\beta=.19, t(195)=2.62, p<.01$; multiple $R=.40, F(7,195)=5.43, p<.001 .^{5}$

To explore this interaction, we examined the simple Age $\times$ Differential Inclusion interactions within each level of account- ability. In the control condition, shown in the upper panel of Figure 1 , only the main effect of differential inclusion was significant, $\beta=.27, t(195)=2.59, p<.05$. Children who showed higher differential inclusion also showed higher differential evaluation. However, in the accountable condition, the effect of differential inclusion, $\beta=.32, t(195)=3.35, p=.001$, and the Differential Inclusion $\times$ Age interaction, $\beta=.34, t(195)=3.61, p<.001$, were both highly significant.

The meaning of the two-way interaction within the accountable condition is relatively straightforward. The relationship between differential inclusion and differential evaluation strengthens significantly with age. This is illustrated in the lower panel of Figure 1 , which depicts the relationship between differential inclusion

\footnotetext{
${ }^{3}$ Analyses of individual items are not reported in detail here for reasons of space and clarity and because they do not substantively alter the findings or conclusions. For the means in Table 1, analyses of variance (ANOVAS subsumed by the regression analyses in the body of the article) revealed significant effects of member on out-group inclusion, $F(1,203)=56.58$, $p<.001, \eta^{2}=.219$, and in-group inclusion $F(1,203)=34.15, p<.001$, $\eta^{2}=.144$, and a significant Condition $\times$ Member interaction effect on in-group inclusion, $F(1,202)=4.55, p<.05, \eta^{2}=.022$. Inclusion of the normative and deviant members differed more in the accountable condition, $F(1,203)=32.49, p<.001, \eta^{2}=.214$, than in the control condition, $F(1,203)=6.70, p=.01, \eta^{2}=.074$. For member evaluations, there was a significant effect of member, $F(1,204)=33.65, p<.001, \eta^{2}=.142$, and Condition $\times$ Member interaction, $F(1,204)=7.36, p<.01, \eta^{2}=$ .035. Normative and deviant members were evaluated more differently in the accountable condition, $F(1,204)=38.94, p<.001, \eta^{2}=.255$, than in the control condition, $F(1,204)=4.72, p<.05, \eta^{2}=.046$.

${ }^{4} M_{\text {intergroup bias }}=2.12, S D=1.74$, possible range $=-4$ to 4 $M_{\text {differential inclusion }}=1.46, S D=2.44$, possible range $=-8$ to 8 $M_{\text {differential evaluation }}=0.49, S D=1.48$, possible range $=-4$ to 4 Correlations among these difference scores were as follows: $r_{\text {intergroup bias-differential inclusion }}=.14, p=.055, r_{\text {intergroup bias-differential evaluation }}=$ $.23, p<.001, r_{\text {differential inclusion-differential evaluation }}=.28, p<.001$.

${ }^{5}$ Otherwise, the full factorial regression analysis revealed significant main effects of intergroup bias $(\beta=.21, p<.01)$ and differential inclusion $(\beta=.25, p<.001)$. The Intergroup Bias $\times$ Differential Inclusion inter action remained significant $(\beta=.24, p<.01)$, and the Differential Inclusion $\times$ Age $\times$ Intergroup Bias interaction remained significant $(\beta=$ $.16, p<.05)$.
} 
Table 2

Zero-Order Correlations Among Variables

\begin{tabular}{|c|c|c|c|c|c|c|c|c|c|c|}
\hline Variable & 1 & 2 & 3 & 4 & 5 & 6 & 7 & 8 & 9 & 10 \\
\hline 1. Age & - & & & & & & & & & \\
\hline 2. General in-group evaluation & -.05 & - & & & & & & & & \\
\hline 3. General out-group evaluation & -.06 & $-.18^{* *}$ & - & & & & & & & \\
\hline 4. Normative inclusion by in-group & .01 & $.26^{* * *}$ & -.09 & - & & & & & & \\
\hline 5. Normative inclusion by out-group & $-.23^{* *}$ & .01 & $.21^{* * *}$ & -.09 & - & & & & & \\
\hline 6. Deviant inclusion by in-group & $-.26^{* * * *}$ & $.18^{* * *}$ & .08 & $.21^{* * *}$ & $.26^{* * * *}$ & - & & & & \\
\hline 7. Deviant inclusion by out-group & .02 & .06 & .01 & .11 & -.06 & -.02 & - & & & \\
\hline 8. Evaluation of normative & .11 & $.29^{* * * *}$ & $-.15^{*}$ & $.28^{* * * *}$ & .02 & $.16^{*}$ & .13 & - & & \\
\hline 9. Evaluation of deviant & -.02 & $.12^{\dagger}$ & $.14^{*}$ & .07 & $.30^{* * * *}$ & $.44^{* * * *}$ & .11 & $.18^{*}$ & - & \\
\hline 10. Multiple classification score & $.34^{* * * *}$ & .03 & -.08 & .04 & -.12 & -.09 & -.03 & .01 & -.09 & - \\
\hline
\end{tabular}

${ }^{\dagger} p<.10 .{ }^{*} p<.05 .{ }^{* *} p<.01 .{ }^{* * *} p<.001$.

and differential evaluation as a function of age (defined for these purposes as 1 standard deviation below and above the mean age of all participants, respectively). Among younger children, there was no significant relationship between differential inclusion and differential evaluation, $B=-0.01, t(195)=0.10$, whereas among older children, the relationship was highly significant, $B=0.38$, $t(195)=3.97, p<.001$, such that older but not younger children related their perceptions of differential inclusion to their differential evaluations of members. Older children who did not believe other group members would judge normative and deviant members differently did not evaluate those members differently themselves. However, older children who perceived high levels of differential inclusion among their peers responded to accountability by similarly differentiating between normative and deviant members in their own evaluations. We further checked the simple slopes for effects of age within levels of differential inclusion. When they perceived low differential inclusion, older children showed significantly less differential evaluation than did younger children, $B=$ $-0.21, t(195)=2.27, p<.05$. When they perceived high differential inclusion, older children showed marginally significantly more differential evaluation than did younger children, $B=0.23$, $t(195)=1.97, p<.052$. Thus, the three-way interaction shows that perceptions of differential inclusion become especially influential when peer accountability is heightened, and this influence gains momentum with increasing age. This pattern is consistent with the intragroup accountability hypothesis.

\section{Replication of Relationships Among Intergroup and Intragroup Judgments}

The present data also provided an opportunity to test whether relationships among variables replicate previous findings from this intergroup context (Abrams, Rutland, Cameron, \& Marques, 2003) but with a wider age range and a slightly different measure of intergroup bias. To the extent that the form of interactions obtained in previous studies (Abrams, Rutland, \& Cameron, 2003; Abrams, Rutland, Cameron, \& Marques, 2003) were replicated, this would provide convergent validation for the idea that the same underlying processes are at work.

Motivational hypothesis. The DSGD model assumes that as children develop greater sensitivity to peer group norms and greater social experience, there should be a stronger relationship between intergroup differentiation and intragroup differentiation.
Thus, older children who are motivated more strongly to support their in-group will also base their differential evaluation judgments more strongly on their differential inclusion judgments.

General intergroup bias was significantly positively related to differential evaluation, as expected $(r=.23, p<.001$; see also the relationships among the constituent items in Table 2). To map the present findings onto those of Abrams, Rutland, and Cameron (2003) and Abrams, Rutland, Cameron, and Marques (2003), we examined whether the impact of differential inclusion on differential evaluation was moderated by intergroup bias and whether this effect was larger among older children. We therefore included intergroup bias as a predictor in the regression analysis. Over and above the effects reported previously, this yielded only two significant effects involving intergroup bias.

There was a significant Age $\times$ Intergroup Bias interaction, $\beta=$ $.22, t(192)=3.11, p<.005$. In line with the findings of Abrams, Rutland, Cameron, and Marques (2003), the relationship between intergroup and intragroup bias strengthened with age. Figure 2 shows the regression slopes for differential evaluation when age and intergroup bias are 1 standard deviation below and above their respective means. Simple slopes analysis revealed that among younger children, the relationship between intergroup bias and differential evaluation was nonsignificant, $B=0.06, t(192)=$ 0.83 , whereas among older children the relationship was significant, $B=0.39, t(192)=4.43, p<.001$. Specifically, the more intergroup bias they expressed, the more older children favored the normative member over the deviant member. Comparison of the simple slopes for age among children who showed lower or higher intergroup bias showed that there was a nonsignificant reduction in differential evaluation with age when intergroup bias was low, $B=$ $-0.11, t(192)=1.37, p>.17$, but a significant increase in differential evaluation with age when their intergroup bias was high, $B=0.23, t(192)=3.13, p<.005$.

In addition, there was a significant Intergroup Bias $\times$ Differential Inclusion interaction, $\beta=.24, t(192)=3.59, p<.001$, multiple $R=.50$. Consistent with the predictions based on Abrams, Rutland, and Cameron (2003), the relationship between differential inclusion and differential evaluation was larger among children who also showed more intergroup bias. Specifically, among children who showed less intergroup bias, the simple slope between differential inclusion and differential evaluation was nonsignificant, $B=-0.01, t(192)=0.27$, whereas among children 
who showed more intergroup bias, the relationship was positive and significant, $B=0.30, t(192)=5.90, p<.001$. In addition, whereas there was no relationship between intergroup bias and differential evaluation among children who perceived low differential inclusion, $B=-0.04, t(192)=0.98$, intergroup bias and differential evaluation were strongly positively associated among children who perceived high differential inclusion, $B=0.39$, $t(192)=8.80, p<.001$. Figure 3 shows the slopes describing the relationship to differential evaluation when values of differential
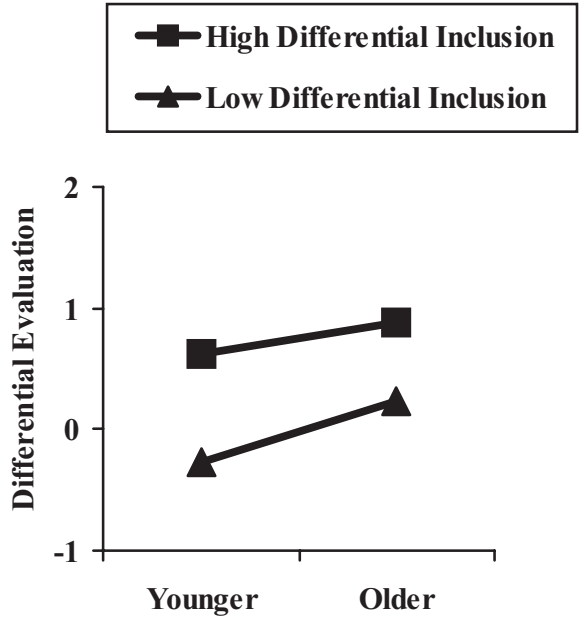

Control

Condition

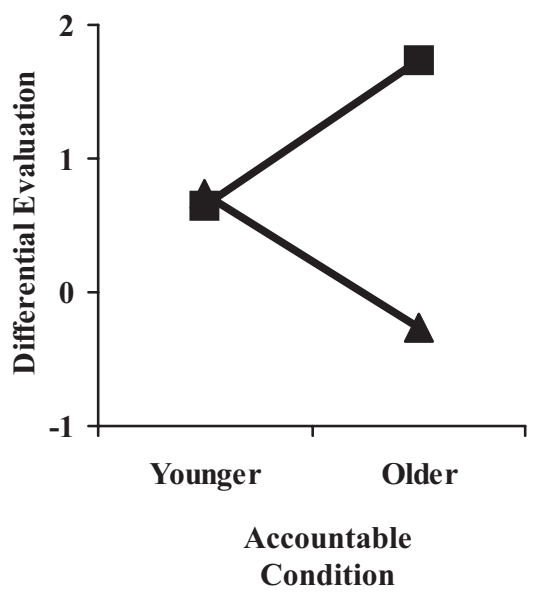

Figure 1. Evaluation of normative group member minus evaluation of deviant group member (differential Evaluation) as a function of condition, age, and differential inclusion. Values for differential evaluation were derived from the regression analysis, within which condition, differential inclusion, age, and their two-way and three-way interactions were used as predictors. Differential inclusion is in-group inclusion minus out-group inclusion rating for the normative member minus the same score for the deviant member. In this figure, to represent younger and older age groups, and for high and low differential inclusion, we substituted values 1 standard deviation above and below the means for those variables.

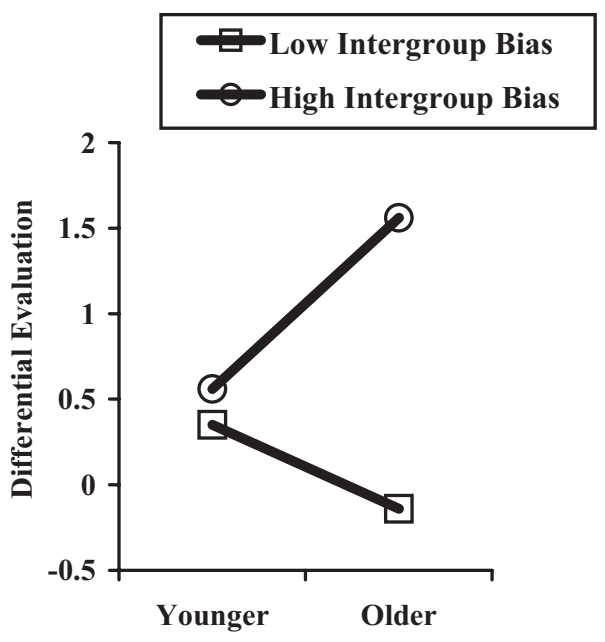

Figure 2. Differential evaluation of in-group members as a function of age and intergroup bias. Intergroup bias was derived by subtracting the rating of the out-group from the rating of the in-group. Values for differential evaluation were derived from the regression analysis, within which differential inclusion, age, intergroup bias, and their two-way and threeway interactions were used as predictors. In this figure, to represent younger and older age groups, and for high and low differential inclusion, we substituted values 1 standard deviation above and below the means for those variables.

inclusion and intergroup bias are 1 standard deviation above and below their respective means. ${ }^{6}$

\section{Multiple Classification Skill}

We hypothesized that multiple classification skill may provide a cognitive underpinning for children's evaluation of groups and group members and, thus, may at least in part account for the development of subjective group dynamics. We were agnostic regarding the relationship between multiple classification and differential inclusion. Scores on the ordinally scored multiple classification task were highly significantly related to age $(r=.34, p<$ $.001)$. However, these scores were not significantly related to differential inclusion, differential evaluation, or intergroup bias (all $r \mathrm{~s}<.12$, all $p \mathrm{~s}>.10$ ), and this thus precludes the possibility of mediation. Moreover, when we tested possible interaction effects between cognitive ability and age, none were significant.

The possibility remained that the ordinal scaling of this measure missed important differences that might be associated with perfor-

\footnotetext{
${ }^{6} \mathrm{We}$ examined effects of school using multilevel modeling. The intraclass correlations were all $<.07$, and no Level 2 (school) effects were significant. Level 1 effects remained consistent with those reported in the text: the Age $\times$ Condition interaction effect on intergroup bias, $t(206)=$ 2.29, $p=.023$; the relationship between age and differential inclusion, $t(203)=4.34, p<.001 ;$ the marginal effect of condition on differential inclusion, $t(203)=1.82, p=.07$; the significant Age $\times$ Condition $\times$ Differential Inclusion interaction effect on differential evaluation, $t(203)=$ 2.67, $p=.008$; the Age $\times$ Intergroup Bias interaction effect on differential evaluation, $t(203)=3.37, p=.001$; and the Differential Inclusion $\times$ Intergroup Bias interaction effect on differential evaluation, $t(203)=4.39$, $p<.001$.
} 

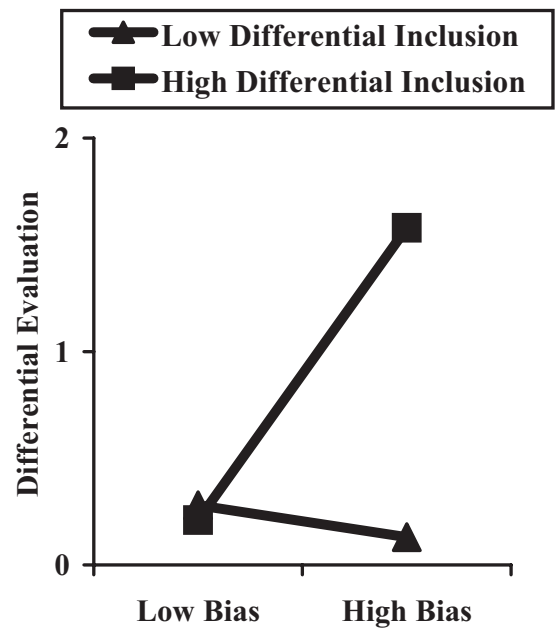

Figure 3. Differential evaluation of in-group members as a function of differential inclusion and intergroup bias. Values for differential evaluation were derived from the regression analysis, within which differential inclusion, age, intergroup bias, and their two-way and three-way interactions were used as predictors. In this figure, to represent high and low intergroup bias and for high and low differential inclusion, we substituted values 1 standard deviation above and below the means for those variables.

mance and competence factors (i.e., that it confounded these). To investigate whether different dichotomizations of the classification ability measure might better predict the dependent variables, we examined the three alternative dichotomizations described above. All three were significantly related to age, though none as highly as the ordinal index. Specifically, older children were more likely to correctly classify the stimuli regardless of whether they could justify the classification $(r=.26, p<.001)$; older children were more likely to correctly justify the classification regardless of whether it had to be shown to them $(r=.30, p<.001)$; and older children were more likely to correctly classify and justify the classification than they were to fail either of these aspects $(r=.30$, $p<.001)$. None of these dichotomous measures were significantly related to the dependent measures. Therefore, although as predicted, older children did show better multiple classification skill (regardless of the index used), we found no support for the hypothesis that multiple classification skill would mediate the relationship between age and the dependent variables.

\section{Discussion}

Several findings emerged clearly from this study. First, as anticipated, older children's intergroup bias and differential evaluation were both affected by in-group accountability. Significantly, these findings extend the DSGD model by confirming that older children are more sensitive to peer group norms when forming their intergroup judgments and evaluations of individual normative and deviant group members. Second, though multiple classification skill increased with age, it was unrelated to children's intergroup and intragroup differentiation. These findings have important implications for CDT (Aboud, 1988; Bigler, 1995; Katz et al., 1975) and attempts to explain the development of social knowledge using underlying stages of cognitive develop- ment. Third, within middle childhood, the developmental differences in relationships among differential inclusion, differential evaluation, and intergroup bias were in line with previous research using a different intergroup context (Abrams, Rutland, \& Cameron, 2003), and they consolidated marginal effects from a smaller scale study in a similar context (Abrams, Rutland, Cameron, \& Marques, 2003). Older children's judgments of deviant members (differential evaluations) more strongly reflected their increasing understanding of the relationship between the individuals' behavior and their group membership (differential inclusion). The findings are summarized briefly below, and then their implications are discussed further.

\section{Intergroup Judgments}

The present measure of intergroup bias was based on group preference rather than simple favorability, but in other respects, the relationships between this measure and the others in the study are completely in line with those in Abrams, Cameron, and Rutland (2003) and Abrams, Cameron, Rutland, and Marques (2003). Regardless of age, children expressed significant bias in favor of the in-group summer school. Moreover, intergroup bias increased with age when the salience of the loyalty norm was heightened by making children accountable to in-group members. This is consistent with the intergroup accountability hypothesis that older children should be more sensitive to peer group norms.

As expected, multiple classification skill was significantly associated with age. In fact, the relationship was highly comparable to the correlation of .36 within a 5-10 year age range obtained by Bigler and Liben (1992), who used a four-task multiple classification skills measure $(\alpha \mathrm{s}=.70$ in a pretest and .90 in a posttest; $N=75$ ). Thus, it seems reasonable to believe that the present measure was sufficiently sensitive to detect variations in multiple classification skill. Despite finding that multiple classification skill was significantly better among older children, we did not find that intergroup bias decreased with increasing multiple classification skill or with age, as might have been predicted by CDT (Aboud, 1988; Katz, 1976; Lambert \& Klineberg, 1967). This finding is consistent with a growing body of research suggesting that intergroup attitudes may not be significantly linked to multiple classification skill (e.g., Abrams, Cameron, \& Rutland, 2003; Abrams, Cameron, Rutland, \& Marques, 2003); Abrams, Rutland, Cameron, Ferrell, \& Pelletier, 2006; Bigler, Brown, \& Markell, 2001; Cameron \& Rutland, in press; Rutland, 1999, 2004; Rutland et al., 2005) or, indeed, more basic classification skill (Patterson \& Bigler, 2006). Furthermore, we found no evidence that multiple classification skill was related to intragroup judgments, which provides an important further line of evidence. Together, this research suggests that the stages of cognitive development associated with the development of multiple classification skill may not be especially influential on these forms of social judgment.

One possible explanation for the absence of a relationship between multiple classification skill and intergroup bias may be suggested by the absence of an age trend in intergroup bias itself. This may in part be a product of the accountability manipulation. Previous developmental research on accountability cues and intergroup attitudes showed that children were less racially prejudiced because of their expectation that adults may disapprove of intergroup bias (Rutland et al., 2005). In contrast, the present research 
shows that national intergroup bias can be increased with age if peer group loyalty norms are salient. This suggests that an important avenue for future research will be to investigate how children develop sensitivity to different types of audience when inferring norms for judgments about groups and their members.

\section{Intragroup Judgments}

In line with the DSGD model, children judged that normative members were more likely than deviant members to be accepted by peers. More important, there was a significant developmental trend in the children's understanding of differential inclusion, with the older children performing better than younger children. This finding provides partial support for CDT's expectation that older children should engage in more individuated judgments (Aboud, 1988; Bigler, 1995; Katz et al., 1975). However, significantly, we found no support for the idea that multiple classification skills are related to intragroup differentiation. Although age was significantly related to both differential inclusion and multiple classification skills, the latter were unrelated to one another. This does not necessarily mean that multiple classification skills play no role in some aspect of subjective group dynamics. However, we found no evidence for the possibility that multiple classification skill underpins judgments about group inclusion.

On the basis of the notion that older children should give less weight to group memberships, another possibility is that CDT might predict that older children will evaluate a group member who is more partisan (i.e., normative in this context) less positively than they will an even-handed (i.e., deviant) group member. Indeed, children could have viewed the deviant member as more generally inclusive and perhaps higher in social competence (see Erwin, 1993; Schneider, 1993). Thus, children could justifiably have evaluated the deviant member more favorably than the normative member. But this did not occur. In line with the DSGD model, the normative in-group member was evaluated more positively than the deviant member. Moreover, this effect increased significantly in the accountable condition.

Consistent with our intragroup accountability hypothesis, when they were accountable, older children related their perceptions of differential inclusion more strongly to their differential evaluations than did younger children. This highlights the fact that social competence may mean different things in different contexts (Durkin, 1995). A socially competent child is likely to be one who understands about adherence to the relevant group norms in a particular intergroup context and to a relevant audience (Abrams \& Brown, 1989; Rutland et al., 2005). This argues for a revision of the view that bullies (i.e., children who derogate a deviant member) or aggressors have poor social understanding and poor socialcognitive skills (Crick \& Dodge, 1994; Dodge, Pettit, McClaskey, \& Brown, 1986; McKeough, Yates, \& Marini, 1994). Indeed, research suggests that bullies often have a good understanding of others' emotions and their minds in different social situations (Dunn, 2004; Sutton, Smith, \& Swettenham, 1999). Social understanding and related social-cognitive skills are especially important for indirect methods of bullying such as social exclusion within a group (Bjorkqvist, Lagerspetz, \& Kaukainen, 1992), because the bully is likely to require some understanding of group dynamics. It is interesting to note that, in line with our age moderation effects, research suggests that indirect forms of bully- ing increase with age, whereas more direct methods decline (Rivers \& Smith, 1994).

\section{The Relationship Between General Intergroup Bias, Intragroup Differentiation, and Age}

In line with the DSGD and previous findings, general intergroup bias and differential evaluation were positively related. Moreover, as predicted, the relationship between intergroup bias and differential evaluation was significantly larger among older children. In addition, consistent with the findings of Abrams, Rutland, and Cameron (2003), older children who expressed greater intergroup bias also related their perceptions of differential inclusion more strongly to their differential evaluation of normative and deviant group members. The replication of these developmental trends is important because of the slight change in the measure of intergroup bias. Thus, regardless of whether intergroup bias was measured in terms of favorability (Abrams, Rutland, Cameron, \& Marques, 2003) or intergroup preference, older children's intergroup judgments were related to their intragroup evaluations more systematically through their perceptions of differential inclusion. Note that children did not actually have to see peer group reactions, they merely had to imagine them. Peer group social pressure was therefore represented psychologically and did not have to take place directly. This is consistent with the idea that the dynamics of groups are represented psychologically and have an important role in judgments of groups and their members. These findings suggest that developmental processes through middle childhood introduce differential inclusion as a social-perceptual basis, and perhaps a sense of justification, for differential evaluation of group members (Killen, Lee-Kim, McGlothlin, \& Stangor, 2002).

\section{Limitations and Implications}

By necessity, the present research addressed only part of the development of subjective group dynamics. One limitation is that we did not ask children to judge members from the out-group. Although judgments of out-group members are useful for detecting the black sheep effect (Marques et al., 1988), it is not necessary to examine these when testing the relationships between intergroup and intragroup judgment. Nonetheless, it is conceivable that children's evaluations of out-group members might show different relationships with either accountability or multiple classification skills (see Aboud, 2003; Nesdale, 2001).

A further limitation is that our focus was only on deviance in terms of the prescriptive in-group loyalty norm. It may be that other types of deviance (e.g., in terms of appearance, personality, morality, or legalistic rules) carry different connotations and attract different evaluations (cf. Killen, Lee-Kim, et al., 2002). However, it still seems likely that older children will have a more sophisticated understanding of who endorses particular norms and rules, and members of different groups will have different norms. The manner in which children make use of this understanding when they judge the actions and attitudes of others is worthy of investigation in future research.

The summer school intergroup context could be viewed as relatively novel and free from cultural or historical content. Membership of the summer schools was transitory and presumably carried less meaning than children's memberships in longstanding 
social categories such as gender, ethnicity, and nationality or membership in their regular schools (see also Killen \& Stangor, 2001). However, the level of general intergroup bias was quite high, with a large effect size, so it is not inevitable that using groups with more history or meaning might have resulted in stronger effects. Indeed, with some types of group membership differential evaluations of members within groups may be inhibited, particularly when children are accountable to adults (see Rutland et al., 2005). In addition, although the present research was conducted in a relatively individualistic country (but see Oyserman, Kemmelmeier, \& Coon, 2002), it may be that children in more collectivist cultures have different norms regarding the treatment of in-group and out-group deviant members (Killen, Crystal, \& Watanabe, 2002; Smith \& Bond, 1994; Triandis, 1995).

Owing to our theoretical priorities and practical limitations, there was a limit to the amount we could ask the children; therefore, the present research did not investigate other variables that could potentially inform the DSGD model. For example, children's developing motivational processes and perceptions of subjective validity of the group norms may relate to the judgments of group members (Abrams, Randsley de Moura, Hutchison, \& Viki, 2005; Marques et al., 1998). In addition, future research is also needed to investigate when and why children might distinguish effects of the direction of deviance (e.g., opposing the group vs. being an extremist member) from the effects of the amount of deviance (large or small absolute differences from normative members; Abrams et al., 2000). These issues may require that different or more complex measurement techniques be devised for use with children. In addition, it would be useful to learn more about children's developing sensitivity to the degree of homogeneity within the group, because this may affect the amount of differential evaluation of the members, as has been found in adult research (Marques et al., 2001).

There could be several reasons why the present results did not provide unequivocal support for CDT (Aboud, 1988; Katz, 1976; Lambert \& Klineberg, 1967). A relatively basic single task was used to test children's multiple classification skill. It may be useful to use a more extensive set of items in the future. However, multiple classification scores were reliably associated with age, suggesting that the task did tap into some aspects of the cognitive development of multiple classification skill. ${ }^{7}$ A further possibility is that multiple classification skill may play a role earlier in the processes that we have been investigating. For example, it may be that it has a more important role in the detection of differences between individuals and groups, even if it is not implicated in the judgments that are subsequently made about those differences. This is an avenue that will need to be explored in future research.

The literature on perspective taking and theory of mind (Harris, Johnson, Hutton, Andrews, \& Cooke, 1989; Nguyen \& Frye, 1999; Symons, McLaughlin, Moore, \& Morine, 1997) suggests that children's understanding of multiple perspectives develops earlier in the physical domain than in the social domain. It seems likely that children's ability to adopt multiple perspectives, particularly social perspectives, could relate to their inferences about differential inclusion. For this reason, it would be desirable for future research to measure these perspective-taking skills. In particular, the DSGD model would anticipate that children develop an understanding of group dynamics, which enables them to predict and interpret how group members will respond toward normative and deviant group members (Abrams et al., 2005). There are likely to be both functional and social-developmental reasons why such a capacity should develop. Functionally, children need to understand the rules of acceptance and rejection in groups so as to avail themselves of valued resources that groups can provide (cf. Kurzban \& Leary, 2001). Also, with increasing experience of group membership, children will be directly exposed to peer pressure to conform to group norms (Erwin, 1993; Rutland et al., 2005), and they may thereby develop the ability to generalize the "ground rules" of group membership (cf. Zdaniuk \& Levine, 2001).

The developmental literature on peer rejection has traditionally focused on individual features (e.g., aggression, disruptive behavior) associated with children's social rejection (e.g., Langlois \& Stephan, 1981; Mostow, Izard, Fine, \& Tentacosta, 2002; Newcomb et al., 1993). A similar focus on particular characteristics of individuals is found in the majority of developmental research that has portrayed peer group bullying as social interaction limited to a psychologically disturbed individual and his or her victims (Craig, 1998; Hawker \& Boulton, 2000). However, it is possible that these personal characteristics of the victim and bully result from the children's social experiences and the peer group context (Dunn, 2004; Hymel et al., 2002). For example, children may show aggression because they have been socially excluded on the basis of their deviant behavior (i.e., not conforming to the normative expectations of their social group or not acting according to the reputation of the group).

The present research highlights the fact that judgments of, and reactions to, individual children (i.e., peer acceptance and rejection) may be determined partly by the intergroup context (see also Abrams, Hogg, \& Marques, 2005; Abrams, Rutland, \& Cameron, 2003; Ojala \& Nesdale, 2004). It is interesting to note that there is a growing body of developmental evidence that contextual peer group norms may play a significant role in bullying and social rejection among children (Chang, 2004; Coie, Dodge, Terry, \& Wright, 1991; Stormshak, Comeau, \& Shepard, 2004). Our research suggests that between the ages of 5 and 12 years, as children develop a more sophisticated understanding of group dynamics, they also have at hand a powerful tool for social control and maintenance of peer group conformity. Thus, developmentally, bullying behavior such as exclusion and victimization of individuals may come to be based more on peer group norms and expectations than on purely interpersonal factors. For example, older children may be more likely to base bullying behavior on whether an individual conforms to in-group prescriptive norms (e.g., misbehaving within the school class, wearing the "correct" in-group clothing) than on idiosyncratic features of an individual (e.g., their personal name or physical attractiveness). In sum, it may be that children become older but wilier in their expressions of intergroup and intragroup evaluations.

\footnotetext{
${ }^{7}$ Other, unpublished data are consistent with those in the present study. Specifically, Abrams, Rutland, Cameron, Ferrell, and Pelletier (2006) found that scores on the shapes and colors multiple classification task loaded on a single factor with scores on three other multiple classification tasks that used line length and style, bears and elephants of different colors, and people of different ages and genders. All four measures were similarly related to age.
} 


\section{Conclusions}

The present findings extend previous research by demonstrating experimentally that the development of subjective group dynamics involves an increase in sensitivity to the normative aspects of the intergroup context. Older children were more sensitive to peer group norms, and when accountable to their peers, they showed more general intergroup bias and related expected inclusion of normative and deviant members more strongly to evaluations of those members. These findings do not appear to be explained by children's multiple classification skill. The findings also extend previous developmental research on evaluations and justifications of exclusion (Killen, Crystal, \& Wantanabe, 2002), originating from social-cognitive domain theory (Smetana, 1995; Turiel, 1998), by indicating why with age children increasingly use social-conventional justifications such as group functioning (e.g., "the group won't work well with someone different in"). The role of social-conventional knowledge about differential inclusion offers an important new avenue of research that may link social interaction processes and social conceptions about peer groups in middle childhood and beyond.

Taken together, these results provide a new line of support for the DSGD model through a test of its key propositions, a better understanding of peer rejection when group membership is salient, and a valuable replication of previous findings. Children who develop the ability to attend to more individuating information also show evidence of combining the processes of intragroup and intergroup comparison. By the age of 12 years, the psychological processes may be well established that underpin the social regulation of peer group members' behavior and facilitate peer rejection or bullying within intergroup contexts. Future research is needed to investigate additional cognitive and sociocognitive antecedents of these processes, to explore other intergroup contexts (e.g., particularly ethnic, gender, and minimal groups), and to explore how other aspects of social and moral development (Killen, Pisacane, Lee-Kim, \& Ardila-Rey, 2001) affect children's judgments of individuals within groups.

\section{References}

Aboud, F. E. (1988). Children and prejudice. Oxford, England: Blackwell. Aboud, F. E. (2003). The formation of in-group favoritism and out-group prejudice in young children: Are they distinct attitudes? Developmental Psychology, 39, 48-60.

Abrams, D., \& Brown, R. J. (1989). Self-consciousness and social identity: Self-regulation as a group member. Social Psychology Quarterly, 52, 311-318.

Abrams, D., Hogg, M. A., \& Marques, J. M. (Eds.). (2005). The social psychology of inclusion and exclusion. New York: Psychology Press.

Abrams, D., Marques, J. M., Bown, N., \& Dougill, M. (2002). Anti-norm and pro-norm deviance in the bank and on the campus: Two experiments on subjective group dynamics. Group Processes and Intergroup Relations, 5, 163-182.

Abrams, D., Marques, J. M., Bown, N. J., \& Henson, M. (2000). Pro-norm and anti-norm deviance within and between groups. Journal of Personality and Social Psychology, 78, 906-912.

Abrams, D., Randsley de Moura, G.., Hutchison, P., \& Viki, G. T. (2005). When bad becomes good (and vice versa): Why social exclusion is not based on difference. In D. Abrams, M. A. Hogg, \& J. M. Marques (Eds.), The social psychology of inclusion and exclusion (pp. 161-190). New York: Psychology Press.
Abrams, D., \& Rutland, A. (in press). The development of subjective group dynamics. In. S. Levy \& M. Killen (Eds.), Intergroup relations: An integrative developmental and social psychological perspective. Oxford, United Kingdom. Oxford University Press.

Abrams, D., Rutland, A., \& Cameron, L. (2003). The development of subjective group dynamics: Children's judgments of normative and deviant in-group and out-group individuals. Child Development, 74, $1840-1856$.

Abrams, D., Rutland, A., Cameron, L., Ferrell, J., \& Pelletier, J. (2006, January). Group know how: Development of subjective group dynamics and the interplay of intergroup and intragroup relations. Paper presented at the Society of Personality and Social Psychology Preconference on Groups and Intergroup Relations, Palm Springs, FL.

Abrams, D., Rutland, A., Cameron, L., \& Marques, J. M. (2003). The development of subjective group dynamics: When in-group bias gets specific. British Journal of Developmental Psychology, 21, 155-176.

Aiken, L. S., \& West, S. G. (1991). Multiple regression: Testing and interpreting interactions. Newbury Park, CA: Sage.

Alvarez, J. M., Ruble, D. N., \& Bolger, N. (2001). Trait understanding or evaluative reasoning? An analysis of children's behavioral predictions. Child Development, 72, 1409-1425.

Banerjee, R. (2002). Audience effects on self-presentation in childhood. Social Development, 11, 487-507.

Banerjee, R., \& Lintern, V. (2000). Boys will be boys: The effect of social evaluation concerns on gender-typing. Social Development, 9, 397-408.

Barenboim, C. (1978). The development of recursive and nonrecursive thinking about persons. Developmental Psychology, 14, 419-420.

Barenboim, C. (1981). The development of person perception in childhood and adolescence: From behavioral comparisons to psychological constructs to psychological comparisons. Child Development, 52, 129-144.

Bigler, R. S. (1995). The role of classification skill in moderating environmental influences on children's gender stereotyping: A study of the functional use of gender in the classroom. Child Development, 66, 1072-1087.

Bigler, R. S., Brown, C. S., \& Markell, M. (2001). When groups are not created equal: Effects of group status on the formation of intergroup attitudes in children. Child Development, 72, 1151-1162.

Bigler, R. S., \& Liben, L. S. (1992). Cognitive mechanisms in children's gender stereotyping: Theoretical and educational implications of a cognitive-based intervention. Child Development, 63, 1351-1363.

Bjorkqvist, K., Lagerspetz, K. M. J., \& Kaukainen, A. (1992). Do girls manipulate and boys fight? Developmental trends in regard to direct and indirect aggression. Aggressive Behaviour, 18, 117-127.

Black-Gutman, D., \& Hickson, F. (1996). The relationship between racial attitudes and social-cognitive development in children: An Australian study. Developmental Psychology, 32, 448-456.

Blanchard, F. A., Crandall, C. S., Brigham, J. C., \& Vaughn, L. A. (1994). Condemning and condoning racism: A social context approach to interracial settings. Journal of Applied Psychology, 79, 993-997.

Cameron, L. \& Rutland, A. (in press). An integrative approach to changing children's intergroup attitudes. In S. Levy \& M. Killen (Eds.), Intergroup relations: An integrative developmental and social psychological perspective. Oxford, United Kingdom. Oxford University Press.

Chang, L. (2004). The role of classroom norms in contextualizing the relations of children's social behaviors to peer acceptance. Developmental Psychology, 40, 691-702.

Coie, J. D., Dodge, K. A., Terry, R., \& Wright, V. (1991). The role of aggression in peer relations: An analysis of aggression episodes in boys' play groups. Child Development, 62, 812-826.

Craig, W. M. (1998). The relationship among bullying, victimization, depression, anxiety, and aggression in elementary school children. Personality and Individual Differences, 24, 123-130.

Crick, N. R., \& Dodge, K. A. (1994). A review and reformulation of social 
information processing mechanisms in children's social adjustment. Psychological Bulletin, 115, 74-101.

Dodge, K. A., Pettit, G. S., McClaskey, C. L., \& Brown, M. A. (1986). Social competence in children. Monographs of the Society for Research in Child Development, 51(2, Serial No. 213).

Dovidio, J. F., \& Gaertner, S. L. (1991). Changes in the expression and assessment of racial prejudice. In H. J. Knopke, R. J. Norrell, \& R. W. Rogers (Eds.), Opening doors: Perspectives on race relations in contemporary America (pp. 119-148). Tuscaloosa: University of Alabama Press.

Doyle, A. B., Beaudet, J., \& Aboud, F. (1988). Developmental patterns in the flexibility of children's ethnic attitudes. Journal of Cross-Cultural Psychology, 19, 3-18.

Dunn, J. (2004). Children's friendships: The beginning of intimacy. Oxford, England: Blackwell.

Durkin, K. (1995). Developmental social psychology: From infancy to old age. Oxford, England: Blackwell.

Erwin, P. (1993). Friendship and peer relations in children. Chichester, England: Wiley.

Golbeck, S. L. (1983). Reconstructing a large-scale spatial arrangement: Effects of environmental organization and operativity. Developmental Psychology, 19, 644-653.

Harris, P., Johnson, C. N., Hutton, D., Andrews, G., \& Cooke, T. (1989). Young children's theory of mind and emotion. Cognition and Emotion, $3,379-400$.

Hartup, W. W. (1983). Peer relations. In E. M. Hetherington (Ed.), Handbook of child psychology, Vol. 4: Socialization, personality, and development (pp. 103-196). New York: Wiley.

Hawker, D. S. J., \& Boulton, M. J. (2000). Twenty years' research on peer victimization and psychosocial maladjustment: A meta-analytic review of cross sectional studies. Journal of Child Psychology and Psychiatry and Allied Disciplines, 41, 441-455.

Hymel, S., Vaillancourt, T., McDougall, P., \& Renshaw, P. D. (2002). Peer acceptance and rejection in childhood. In P. K. Smith \& C. H. Hart (Eds.), Blackwell handbook of childhood social development (pp. 265284). Oxford, England: Blackwell.

Inhelder, B., \& Piaget, J. (1964). The early growth of logic in the child. New York: Norton.

Jahoda, G., Thomson, S. S., \& Bhatt, S. (1972). Ethnic identity and preferences among Asian immigrant children in Glasgow: A replicated study. European Journal of Social Psychology, 2, 19-32.

Jetten, J., Spears, R., \& Manstead, A. S. R. (1997). Strength of identification and intergroup differentiation: The influence of group norms. European Journal of Social Psychology, 27, 603-609.

Judd, C. M., Kenny, D. A., \& McClelland, G. H. (2001). Estimating and testing mediation and moderation in within subjects designs. Psychological Methods, 6, 115-134.

Katz, P. A. (1976). The acquisition of racial attitudes in children. In P. A. Katz (Ed.), Towards the elimination of racism (pp. 125-154). New York: Pergamon Press.

Katz, P. A., Sohn, M., \& Zalk, S. R. (1975). Perceptual concomitants of racial attitudes in urban grade-school children. Developmental Psychology, 11, 135-144.

Killen, M., Crystal, D. S., \& Watanabe, H. (2002). Japanese and American children's evaluations of peer exclusion, tolerance of differences, and prescriptions for conformity. Child Development, 73, 1788-1802.

Killen, M., Lee-Kim, J., McGlothlin, H., \& Stangor, C. (2002). How children and adolescents evaluate gender and racial exclusion. Monographs of the Society for Research in Child Development, 67(4).

Killen, M., Pisacane, K., Lee-Kim, J., \& Ardila-Rey, A. (2001). Fairness or stereotypes? Young children's priorities when evaluating group exclusion and inclusion. Developmental Psychology, 37, 587-596.

Killen, M., \& Stangor, C. (2001). Children's social reasoning about inclu- sion and exclusion in gender and race peer groups contexts. Child Development, 72, 174-186.

Kurzban, R., \& Leary, M. R. (2001). Evolutionary origins or stigmatization: The functions of social exclusion. Psychological Bulletin, 127, 187-208.

Lambert, W. E., \& Klineberg, O. (1967). Children's views of foreign peoples. New York: Meredith.

Langlois, J. H., \& Stephan, C. W. (1981). Beauty and the beast: The role of physical attractiveness in the development of peer relations and social behavior. In S. S. Brehm, S. M. Kassin, \& F. X. Gibbons (Eds.), Developmental social psychology: Theory and research (pp. 152-168). New York: Oxford University Press.

Lawrence, V. W. (1991). Effect of socially ambiguous information on White and Black children's behavioral and trait perceptions. MerrillPalmer Quarterly, 37, 619-630.

Levy, S. R., \& Troise, D. M. (2001, April). Children's social concerns with appearing prejudiced. In C. McKown (Chair), The development and consequences of stereotype processes in childhood. Symposium conducted at the Biennial Meeting of the Society for Research in Child Development, Minneapolis, MN.

Livesley, W. J., \& Bromley, D. B. (1973). Person perception in childhood and adolescence. Oxford, England: Wiley.

MacCallum, R. C., Zhang, S., Preacher, K. J., \& Rucker, D. D. (2002). On the practice of dichomotization of quantitative variables. Psychological Methods, 7, 19-40.

Marques, J. M., Abrams, D., Paez, D., \& Martinez-Taboada, C. (1998). The role of categorization and in-group norms in judgments of groups and their members. Journal of Personality and Social Psychology, 75, 976 988.

Marques, J. M., Abrams, D., \& Serôdio, R. G. (2001). Being better by being right: Subjective group dynamics and derogation of in-group deviants when generic norms are undermined. Journal of Personality and Social Psychology, 81, 436-447.

Marques, J. M., \& Paez, D. (1994). The "black sheep effect": Social categorization, rejection of ingroup deviates and perception of group variability. European Review of Social Psychology, 5, 37-68.

Marques, J. M., Yzerbyt, V. Y., \& Leyens, J.-Ph. (1988). The black sheep effect: Judgmental extremity towards ingroup members as a function of group identification. European Journal of Social Psychology, 18, 1-16.

Martin, C. L. (1989). Children's use of gender-related information in making social judgments. Developmental Psychology, 25, 80-88.

McKeough, A., Yates, T., \& Marini, A. (1994). Intentional reasoning: A developmental study of behaviorally aggressive and normal boys. Development and Psychopathology, 6, 285-304.

Monteith, M. J., Deneen, N. E., \& Tooman, G. D. (1996). The effect of social norm activation on the expression of opinions concerning gay men \& Blacks. Basic and Applied Social Psychology, 18, 267-288.

Mostow, A. J., Izard, C. E., Fine, S., \& Tentacosta, C. J. (2002). Modeling emotional, cognitive, and behavioral predictors of peer acceptance. Child Development, 73, 1775-1787.

Nesdale, D. (2001). Development of prejudice in children. In M. Augoustinos \& K. J. Reynolds (Eds.), Understanding prejudice, racism, and social conflict (pp. 57-73). London: Sage.

Newcomb, A. F., Bukowski, W. M., \& Pattee, L. (1993). Children's peer relations: A meta-analytic review of popular, rejected, neglected, controversial, and average sociometric status. Psychological Bulletin, 111, $99-128$.

Nezlek, J. B. (2001). Multilevel random coefficient analyses of event and interval contingent data in social and personality psychology research. Personality and Social Psychology Bulletin, 27, 771-785.

Nguyen, L., \& Frye, D. (1999). Children's theory of mind: Understanding of desire, belief and emotion with social referents. Social Development, 8, 70-92.

Ojala, K., \& Nesdale, D. (2004). Bullying and social identity: The effects 
of group norms and distinctiveness threat on attitudes towards bullying. British Journal of Developmental Psychology, 22, 19-35.

Oyserman, D., Kemmelmeier, M., \& Coon, H. (2002). Cultural psychology: A new look. Psychological Bulletin, 128, 110-117.

Patterson, M. M., \& Bigler, R. S. (2006). Preschool children's attention to environmental messages about groups: Social categorization and the origins of intergroup bias. Child Development, 77, 847-860.

Peevers, B. H., \& Secord, P. F. (1973). Developmental changes in attribution of descriptive concepts to persons. Journal of Personality and Social Psychology, 27, 120-128.

Plant, E. A., \& Devine, P. G. (1998). Internal and external motivation to respond without prejudice. Journal of Personality and Social Psychology, 75, 811-832.

Powlishta, K. K. (1995). Intergroup processes in childhood: Social categorization and sex role development. Developmental Psychology, 31, 781-788.

Quintana, S. M. (1994). A model of ethnic perspective-taking ability applied to Mexican-American children and youth. International Journal of Intercultural Relations, 18, 419-448.

Quintana, S. M. (1998). Children's developmental understanding of ethnicity and race. Applied and Preventative Psychology, 7, 27-45.

Quintana, S. M. (1999). Role of perspective-taking abilities and ethnic socialization in development of adolescent ethnic identity. Journal of Research on Adolescence, 19, 161-184.

Rivers, I., \& Smith, P. K. (1994). Types of bullying behaviour and their correlates. Aggressive Behavior, 20, 359-368.

Rubin, K. H., Bukowski, W., \& Parker, J. G. (1998). Peer interaction, relationships, and groups. In W. Damon \& N. Eisenberg (Eds.), Handbook of child psychology, Vol. 3: Social, emotional, and personality development (5th ed., pp. 619-700). New York: Wiley.

Ruble, D. N., Alvarez, J., Bachman, M., Cameron, J., Fuligni, A., García Coll, C., \& Rhee, E. (2004). The development of a sense of "we": The emergence and implications of children's collective identity. In M. Bennett \& F. Sani (Eds.), The development of the social self (pp. 29-76). East Sussex, England: Psychology Press.

Ruble, D. N., \& Dweck, C. S. (1995). Self-conceptions, person conceptions, and their development. In N. Eisenberg (Ed.), Review of personality and social psychology: Social development (Vol. 15, pp. 109-139). Thousand Oaks, CA: Sage.

Rutland, A. (1999). The development of national prejudice, in-group favouritism and self-stereotypes in British children. British Journal of Social Psychology, 38, 55-70.

Rutland, A. (2004). The development and self-regulation of intergroup attitudes in children. In M. Bennett \& F. Sani (Eds.) The development of the social self (pp. 247-265). East Sussex, England: Psychology Press.

Rutland, A., Cameron, L., Milne, A., \& McGeorge, P. (2005). Social norms and self-presentation: Children's implicit and explicit intergroup attitudes. Child Development, 76, 451-466.

Schneider, B. H. (1993). Children's social competence in context. Oxford, England: Pergamon Press.

Selman, R. L. (1971). Taking another's perspective: Role-taking development in early childhood. Child Development, 42, 1721-1734.

Selman, R. L. (1980). The growth of interpersonal understanding: Development and clinical analyses. San Diego, CA: Academic Press.

Smetana, J. G. (1995). Morality in context: Abstractions, ambiguities and applications. In V. Ross (Ed.), Annals of child development: A research annual (Vol. 10, pp 83-130). Philadelphia: Jessica Kingsley.

Smith, P. B., \& Bond, M. H. (1994). Social psychology across cultures: Analysis and perspectives. Boston: Allyn \& Bacon.

Stormshak, E. A., Comeau, C. A., \& Shepard, S. A. (2004). The relative contribution of sibling deviance and peer deviance in the prediction of substance use across middle childhood. Journal of Abnormal Child Psychology, 32, 635-649.

Sutton, J., Smith, P. K., \& Swettenham, J. (1999). Bullying and "theory of mind": A critique of the "social skills deficit" view of anti-social behaviour. Social Development, 8, 117-127.

Symons, D., McLaughlin, E., Moore, C., \& Morine, S. (1997). False beliefs about the location of objects and caregivers. Journal of Experimental Child Psychology, 67, 423-447.

Tajfel, H., \& Turner, J. C. (1979). An integrative theory of intergroup conflict. In S. Worchel \& W. G. Austin (Eds.), The social psychology of intergroup relations (pp. 7-24). Monterey, CA: Brooks/Cole.

Teichman, Y. (2001). The development of Israeli children's images of Jews and Arabs and their expression in human figure drawings. Developmental Psychology, 37, 749-761.

Triandis, H. C. (1995). A theoretical framework for the study of diversity. In H. M. Chemers \& Stuart Oskamp (Eds.), Diversity in organizations: New perspectives for a changing workplace (pp. 11-36). Thousand Oaks, CA: Sage.

Turiel, E. (1998). The development of morality. In W. Damon \& N Eisenberg (Eds.), Handbook of child psychology, Vol. 3: Social, emotional, and personality development. (5th ed., pp. 863-932). New York: Wiley.

Yee, M. D., \& Brown, R. (1994). The development of gender differentiation in young children. British Journal of Social Psychology, 33, 183-196.

Zdaniuk, B., \& Levine, J. M. (2001). Group loyalty: Impact of members' identification and contributions. Journal of Experimental Social Psychology, 37, 502-509.

Received March 11, 2005

Revision received July 27, 2006

Accepted October 3, 2006 